Emir. J. Agric. Sci. 2001. (13) : 18-22

http://www.cfs.uaeu.ac.ae/research/ejas.html

\title{
A new technique for collection of semen from dromedary camels
}

\author{
N. A. Hemeida, M. M. Al-Eknah, S. T. Ismail and A. Kh. Al-Haider \\ Camel Research Centre, College of Veterinary Medicine and Animal Resources, \\ King Faisal University, P.O. Box 1757, Al-Ahsa 31982, Saudi Arabia
}

\begin{abstract}
Several semen collection techniques described for other animal species have been modified and adopted for the male camel with variable degree of success. The objectives of this study were to describe a safer and more efficient semen collection technique from male dromedary camels and to assess its use. Six male dromedary camels, aged 8 to 10 years were used. A semen collection area was constructed to allow collection of semen from underneath the male camel. An underground room was designed from steel beams and concrete block with a square loophole in the roof of this room. Semen was collected by a modified bovine artificial vagina through the loophole. A teaser female camel was restrained in sternal recumbancy on a wooden board on the collection area so that the underground loophole was between her thighs. Following training of male camels to enter this semen collection area, successful mounting, intromission and ejaculation took place. This technique proved to be safe for both the animals and the operator. Moreover, it allowed a better view of the copulatory behaviour and ejaculatory pattern.
\end{abstract}

Key words: artifical insemination, semen, vagina, camel, Saudi Arabia.

\section{Introduction}

The camel is one of the most important domesticated animal in the dry regions of Asia and Africa. The Arabian camel has the capability of providing milk and meat better than the cow under the harsh environment. One of the most important factors affecting productivity of the camel is the low reproductive performance. Maintenance of high levels of reproduction is essential not only for profitable production but also to provide ample opportunity for selection and genetic improvement (Novoa, 1970; Elwishy, 1987; Musa et al., 1992; Gordon, 1997; for reproduction efficiency. The efficient collection of high quality semen is important for AI or semen preservation programme. The collection process itself may in fact be the cause of poor fertility or inferior semen quality (Hurtgen, 2000). Semen collection in the camelids presents many difficulties (Pugh, 1999; Tibary and Memon, 1999). Copulation in these species takes place in sitting position with longer duration, besides the slow process of ejaculation (England et al., 1971; Tingari et al., 1986; Bravo and Johnson, 1994; Lichtenwalner et al., 1996; Gordon, 1997).

Several semen collection techniques described for other species have been modified and adopted for the male camelids with variable degrees of success (Tibary and Memon, 1999). The two main techniques used for collection of semen from the dromedary camel are the artificial vagina (AV) and the electro-ejaculation. Collection of semen from the camel using the electro-ejaculation technique requires tranquility of the animal with a special restraint. The ejaculate has lower volume and poor quality, in addition to the possibility of contamination with urine and cellular debris (Tingari et al., 1986; Chaudhary, 1995; Tibary and Memon, 1999).

The AV is considered the most suitable and repeatable technique for collection of semen from the male camelids (Musa et al., 1992; Hassan et al., 1995; Lichtenwalner et al., 1996). Several trials to improve semen collection using AV have been conducted for the male camelids (Anouassi et al., 1992; Musa et al., 1992; Lichtenwalner et al., 1996). Most researchers have focused on improvement of the artificial vagina for better collection of semen. However, the 
latter investigators have attempted collection of semen from the male llama using AV housed inside a surrogate female llama and the males were acclimated to the semen collection area (an elevated wooden chute). This made guidance of the penis towards the AV easier.

The male dromedary camel can be more dangerous and problematic when compared with other male livestock due to its larger size and viciousness. Therefore, this study aimed to describe a safer and more convenient approach for collection of semen from the male dromedary camel with minimal interference.

\section{Materials and Methods}

\section{Animals}

Six males and four non-pregnant female camels (Camelus dromedarius) aged 8-10 years were used in this study. Each male camel was housed separately in 12x6 m paddock and fed 3-4 $\mathrm{kg}$ barley per day. Rhodes grass and water were provided ad libitum. Female camels were housed in large pens and in addition to the ration provided to the males, they were allowed into a pasture for 2-3 hours daily.

\section{Semen Collection System}

The main principle of this approach was to collect semen from the camel by artificial vagina (AV) with the operator in an underground room beneath the collection area. A loophole made up on the roof of this room was designed to pass the artificial vagina through for collection of semen with minimal interruption to the copulation process. This loophole also permitted full observation of the mating behaviour and ejaculatory pattern.

An underground collection room $(230 \mathrm{x}$ $170 \mathrm{x} 185 \mathrm{~cm}$ ) was designed and constructed from iron beams and concrete in tiles (Figures.1\&2). A square loophole $(20 \times 20 \mathrm{~cm})$ fitted with a sliding door was made on the roof. The room was supplied with an entrance, exit, electric current and drainage. It was equipped with a table and an incubator for maintenance of the $\mathrm{AV}$ temperature.

The semen collection area, situated on the collection room, was simply made up from parallel iron bars with an entrance and exit. A wooden board $(380 \times 190 \times 10 \mathrm{~cm})$ was fitted on the floor of the collection area with a rectangular cut $(40$ x $25 \mathrm{~cm})$ opposite to the loophole on the collection room roof (Figure.3).

After several trials of using bull's, ram's, boar's and open-ended artificial vaginae, a new bull's AV was developed for the camel. The modified AV was $30 \mathrm{~cm}$ in length (Figures.4), supplied with a cervix-like cork (inserted at the distal end of the inner liner). The AV was filled with water at $60-70^{\circ} \mathrm{C}$ to give an internal temperature of $40-42^{\circ} \mathrm{C}$.

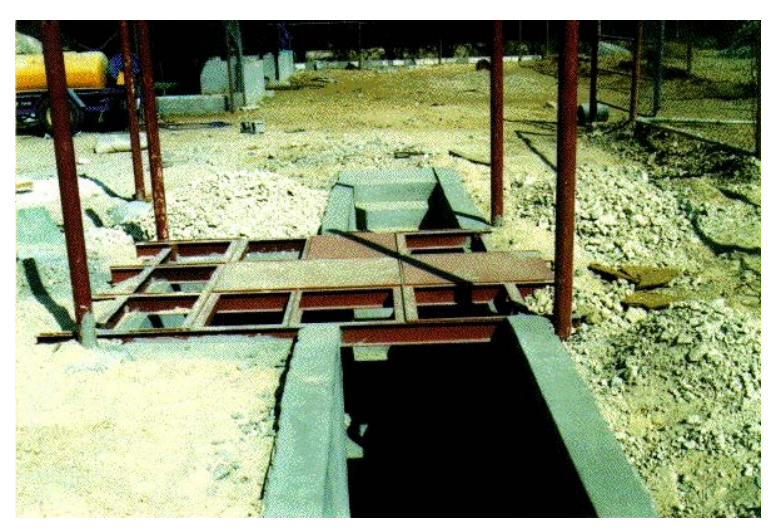

Figure.1. View of the underground room with enterance and exit while under construction.

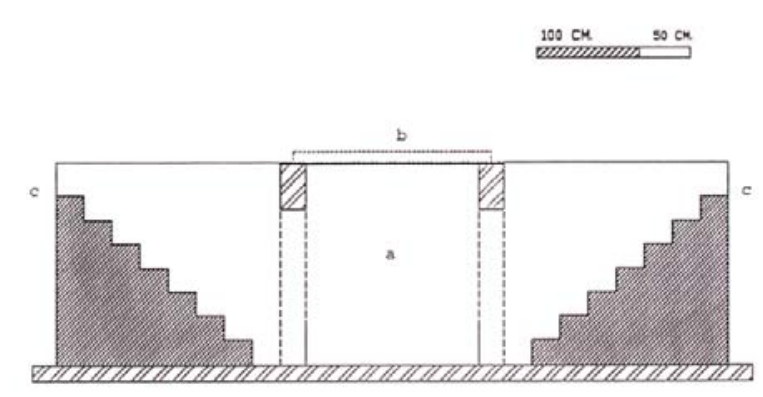

Figure 2. Side view of the underground collection room (a), wooden board (b) and stairs (c). 


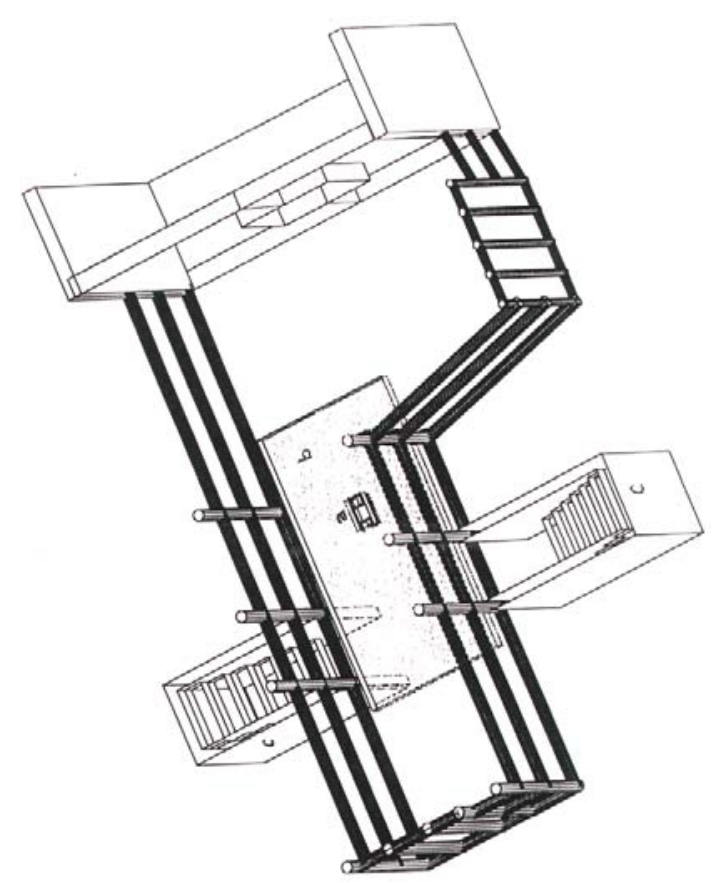

Figure 3. Top view of the collection area showing: collection loophole (a), wooden board (b) and stairs (c) to underground collection room.

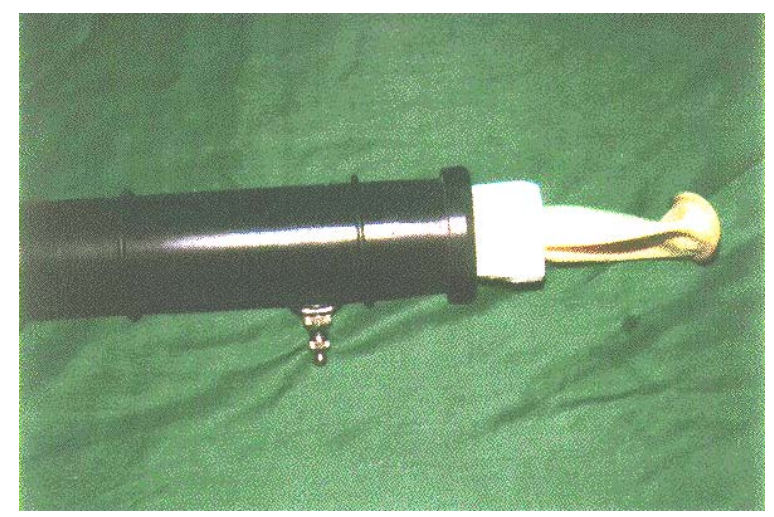

Fig.4. The modified AV showing the inner liner surrounded by cervix-like cork.

Semen collection was performed once a week for each male during the breeding season from November to February. A teaser female camel was tied up in sternal recumbancy on the wooden board of the collection area so that the underground loophole was between her thighs. The male camel was allowed to enter the collection area, sniff, perform flehmen and mount. When the male attempted to introduce his penis in the vagina, the operator in the underground room opened the loophole. The AV was then passed through the loophole and directed towards the penis. In some occasions, another operator was needed to stand at the right side of the bull to help in guiding the penis towards the artificial vagina.

\section{Results}

Most camels with training accepted this approach of semen collection. Therefore, successful mounting, intomission and ejaculation took place. Semen collection was fulfilled in 88 times out of 96 attempts $(84.5 \%)$. For the other $15.5 \%$ attempts, male camels refused to enter the collection area. This technique of semen collection enabled full observation of copulatory behaviour and pattern of ejaculation while the operator was in the underground room. Erection of the penis occurred only after the male had mounted the female in a sitting position. Then the partially erect penis probed the female's perineum to locate the vulva, during which the AV was guided towards the penis (Figure 5). The penis was fully extended upon penetration inside the AV. Following intromission, friction movements of the penis occurred in association with its rotational movements. The male then made himself very close to the female. The appropriate position of the AV just below the female's vulva, between her thighs allowed successful collection without interrupting copulation.

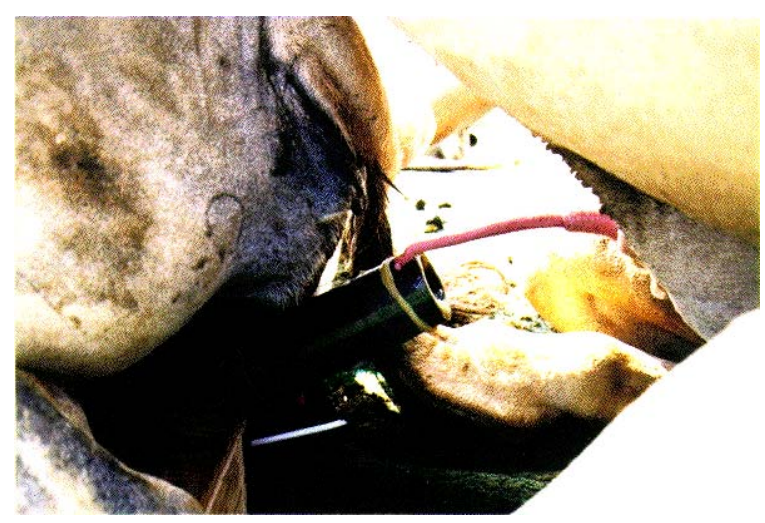

Figure 5. The location of the underground loophole between the thighs of the teaser female camel while the operator passing the AV through the loophole and directing it towards the penis. 
The use of an open-ended AV enabled observing the rapid rotational clockwise movements of the penis. The hook-shaped cartilagenous glans penis made these penile spin very clear. In addition, grasping the glans penis firmly with the gloved hand provoked jets of ejaculation.

The duration of copulation, from initial mounting to final dismounting, ranged from 4 to 20 minutes. Two to eight ejaculations per copulation were collected. Each ejaculation was associated with pelvic thrust. The amount of collected semen ranged from 2 to $23.5 \mathrm{ml}$.

\section{Discussion}

Improvement of semen collection has been considered as an important step for generalisation of artificial insemination in the camel (Sieme et al., 1990). Mating in camelids takes place with the female in a squatting position, which makes copulation nearly at the ground level. It is, therefore, difficult to grasp and direct the penis into the AV (Tingari et al., 1986). The prolonged period of copulation and the slow process of ejaculation add more difficulties for semen collection from the camel (England et al., 1971; Bravo and Johnson, 1994; Lichtenwalner et al., 1996; Gordon, 1997). Thus, the present study demonstrates a useful model for collection of semen from the dromedary camel using AV. The presence of a loophole underneath the collection area facilitated semen collection using the AV without interrupting copulation. The appropriate positioning of the AV underneath the teaser perineum with direct alignment with the base of the penis made semen collection from the camel successful. In this manner, ventral or lateral bending of the penis was avoided. Therefore, this approach allowed better semen discharge throughout the penile urethra. In addition, this pattern of semen collection provides a better view of mating behaviour and full visualisation of ejaculation process. The rutting male camel turns vicious and aggressive, and could be hazardous during semen collection (Arthur et al., 1985; Tingari et al., 1986; Musa et al., 1993). The most important consideration in designing facilities for semen collection is the safety of the handler and collector (Bearden and Fuquay, 1997). This consideration is applicable in this system of semen collection where the operator is totally hidden in the underground room, neither in direct contact with the camel nor under the harsh environmental conditions. The main disadvantage of this pattern of semen collection is that male camels require training to enter the collection area. However, camels trained for this method became habituated to the routine activities and surroundings.

The short modified bull artificial vagina used in this study was to avoid direct contact between the semen and the inner liner, allowing the semen to pass into the collection tube. Most rubber liners have been found to have a deleterious effect on camel spermatozoa (Musa et al., 1992). The artificial vagina was fitted with annular constrictions in order to simulate cervical rings, since the penis of the male camelids penetrates the cervical canal during copulation to deposit semen in the uterus (Franco et al., 1981).

Acknowledgment

The financial support from the Deanship of Scientific Research at King Faisal University is gratefully acknowledged.

\section{References}

Al-Eknah, M. M. 2000. Reproduction in Old World Camels. Animal Reproduction Science 60-61: 583-592.

Anouassi A., Adnani M. and El-Raed 1992. Artificial insemination in the camel requires induction of ovulation to achieve pregnancy. Proceedings of the first International Camel Conference, Dubai, UAE, P 175-177. 
Arthur GH., Al-Rahim AT. and Al-Hindi AB 1985. Reproduction and genital diseases of the camel. British Veterinary Journal 141: 650-659.

Bearden HJ. and Fuquay JW. 1997. Semen Collection. In Applied Animal Reproduction Eds HJ Bearden and JW Fuquay. Prentice-Hall Incorporation, New Jersey, P 147-157.

Bravo PW. and Johnson LW. 1994. Reproductive physiology of the male camelid.. Veterinary Clinics of North America Food Animal Practice 10: 259264.

Chaudhary ZI. 1995. Artificial insemination in the camel: problems and prospects. Journal of Camel Practice and Research 2: 17-26.

Elwishy AB. 1987. Reproduction in the female dromedary camel (Camelus dromedarius): A review. Animal Reproduction Science 15: 273-279.

England BG., Foote WC., Cardozo AG., Matthews DH. and Riera S. 1971. Oestrus and mating behaiour in the llama (Llama glama). Animal Behaviour 19: 722-726.

Franco E., Sumar J. and Varela M. 1981. Eyaculacion en la alpaca (Lama pacos). Proceedings of the IV International Conference on South American Camelids, Punta Arinas, Chille

Gordon I. 1997. Controlled Reproduction in Camelids. In Controlled Reproduction in Horses, Deer and Camelids. Ed. I Gordon .CAB International, Oxon, P 189-208.

Hassan MM., Saed M. and Ul-Muqtadir R. 1995. Semen collection by artificial vagina and cryopreservation of camel spermatozoa. Pakistan Veterinary Journal 15: $105-108$.
Hurtgen JP. 2000. Semen Collection in stallions. In Equine Breeding Management and Artificial Insemination. Ed JC Samper WB Saunders Corporation. Philadelphia P 81-90.

Lichtenwalner AB., Woods GL. and Weber JA. 1996. Seminal collection, Seminal characteristics and pattern of ejaculation in llamas. Theriogenology 46: 293-305.

Musa B., Sieme H., Merkt H. and Hago B. 1992. Artificial insemination in dromedary camels. Proceedings of the first International Camel Conference, Dubai, UAE, P 179-182.

Novoa C. 1970. Reproduction in camelidae: A review. Journal of Reproduction and Fertility 22: 3-20.

Pugh DG. 1999. Male Lama Reproductive Evaluation Proceedings, Society for Theriogenology Annual Meeting Nashville, Tennessee, P 211-216.

Purohit GN. 1999. Biotechnologies in camelid reproduction: Current status and future prospectives. Journal of Camel Practice and Research 6: 1-13.

Sieme H., Merkt H., Musa B., Hago B. and Willem T. 1990. Liquid and deep freeze preservation of camel semen using different extenders and methods. Proceedings of the workshop - Is it possible to improve the reproductive performance of the camel? Paris, France

Tibary A. and Memon MA. 1999 Reproduction in the male South American camelidae. Journal of Camel Practice and Research 6: 235-245.

Tingari MD., Manna MM., Rahim AT., Ahmed AK. and Hamad MH. 1986. Studies on camel semen. I. Electroejaculation and some aspects of semen characteristics. Animal Reproduction Science 12: 213-222. 